\title{
REVIEW: The Cause and Solution Towards Chinese Adolescents Inferior
}

\author{
Liuzixuan Lyu $^{1, *}$ \\ ${ }^{1}$ Beijing E-Town Academy, Beijing, 100007,China. \\ *Corresponding author's Email: Annielyu20041123@gmail.com
}

\begin{abstract}
Adolescents, according to Adler, Erikson, and other psychologists, are at a critical stage in preventing mental health problems from developing or worsening. As a result, the goal of this review is to uncover the mechanisms and solutions to inferiority, a type of negative emotion that is generated easily in adolescents and causes a variety of problems such as reduced living quality, depression, anxiety. Solutions for inferiority include group counselling, ration-emotive therapy, cognitive behaviour therapy, and so on. From the egregious mental environment caused by stresses from various perspectives, this review elucidates and resolves adolescent inferiority, with the hope of assisting more adolescents to eliminate inferiority and acquire higher life quality.
\end{abstract}

Keywords: inferiority, adolescents, therapy.

\section{INTRODUCTION}

As China develops, the attention focused on mental health with adolescents is getting extra concentrated. This condition has led to the awareness of impacts from inferiority, which usually includes maintaining a healthy mental state, succession with grades or career, and other effects on the quality of one's life.

\subsection{Definition of inferiority}

\subsubsection{Western definition of inferiority}

According to individual psychologist Adler, when individuals feel helpless towards the goals that they cannot reach, are unsatisfied with their current performances and conditions, or strongly indicates their value being unnecessary to the society would generate inferiority.[1]. Psychologist P.Janet, concludes that inferiority represents the stubborn thoughts of expected goals; "Overcoming Low self-esteem," written by Fennell, indicates that inferiority is a form of selfdenial. Individuals have the distinction between selfperception and perception from others. For instance, when individuals grow up with negative and traumatizing experiences, they simultaneously accept the negativity [2].

\subsubsection{Chinese definition of inferiority}

There are slight differences in the definition of inferiority from Chinese scholars. Lin had presented his scientific explanation for inferiority as well. Lin concludes that inferiority happens to be the underestimating oneself towards others. Zhou considers inferiority as a subjective negative self-evaluation; Huang believes inferiority is a self-harming emotion. Shi supposes that inferiority complex is an emotional experience that occurs when an individual suggests of themselves as inferior to others in one or more aspects due to some physical or mental defects and other reasons (such as poor attention, memory, judgment, temperament, personality, skills and others.). Inferiority originates from the psychological feelings of incompetence and pain that arise from incompetence in early childhood. Inferiority complexes tend to isolate and alienate people and inhibit self-confidence and a sense of honour. Fei indicates that inferiority generally refers to a negative psychological state in which an individual belittles themselves and concludes they cannot catch up with others because of physical, psychological, or other aspects such as family, work, sometimes because of self-perceived defects [3]. There are also scientific statements that claim inferiority is an emotion that automatically demeans selves. In general, all the statements with different literal explanations radically point to one meaning: inferiority feelings 
appear as a negative emotion and strong self-demeaning psychological implication.

\subsection{The measurement of inferiority}

The Feeling of Inadequacy Scale (FIS), developed by Fleming et al., refined in 1984, was tested to have a score of 0.92 on Cronbach. It is the most commonly used measurement for low self-esteem in China. The FIS consists of five dimensions: academic ability, social confidence, self-esteem, physical ability, and appearance [4]. This measurement used a total point of 733 sections to record and measure the results. The lower the result points are from the FIS system represents the lower chance of experiencing inferiority; the higher the resultant points are, the higher chance of experiencing inferiority.

Scholars usually take inferiority as low self-esteem during research. Consequently, the measurement for inferiority could also use the measurements of selfesteem. Socioeconomic statics (SES) was established by Rosenberg, having the Cronbach score of 0.77 and 0.88 . This measurement is often defined as the measurement to record adolescents' experience with self-value and self-acceptation. It accommodates ten sections with four grading levels; the higher the resultant grading, the greater the chance of experiencing inferiority [5].

To determine the inferiority of majorities, psychologists usually use the Comparative Feeling of Inferiority Index (CFII) developed by Dixon and their team in 1990 [11]. CFII consists of two components, self-rated and family rating, with six scoring levels, and used the T-comparison method to compare the differences between these two components [4].

\subsection{Inferiority and inferiority complex}

Different individuals have their possible reason that could have been the root of their bad feelings. Even though inferiority does not count as a mental disorder, it does quickly develop into an inferiority complex. The study of implicit low self-esteem began with the "inferiority complex" proposed by A. Adler. When an individual does not address the difficulties but rather paralyzes himself with a sense of superiority, his feelings of inferiority build-up and an "inferiority complex" develop. In 1927, Heidbreder conducted a study on the "inferiority complex" and pointed out that implicit inferiority is approximately distributed in ordinary people and exists in different degrees in every person [11].

\subsection{Theory of inferiority}

\subsubsection{Alder development inferior feelings.}

Alder indicates that bad feeling is a common mental experience for people as humans pursue the status and better living experience. According to Alder, children objectively have inferiority due to physical defectives; this brings diffidence and poor quality with personality. Alder then found that individuals have different severity of inferiority, and no one can tolerate inferiority for a long term [6]. Humans will take different kinds of actions to reduce the anxiety and nervousness from inferiority [5].

\subsubsection{Ericson eight stages of development}

Erikson has the consideration of eight developmental stages of individuals from birth to death. The eight stages include Infancy (essential trust vs mistrust), stage searching for courage; early childhood (autonomy vs shame and doubt), stage searching for knowing when; play age (initiative vs guilt), stage searching for tenacity; school-age (industriousness vs inferiority), stage searching for efficacy; adolescence (identity cohesion vs role confusion), stage searching for belonging; young adulthood (intimacy vs isolation), stage searching for mutual loving; adulthood (generativity vs self-absorption), stage searching for needed-ness; old age wisdom (integrity vs despair), stage searching for inner peace [6]. Despite that individuals have different experiences and backgrounds, every human has specific periods to overcome each stage as developing. According to Erikson, if children in the fourth stage cannot overcome obstacles that prevent them from completing the mission, this will generate inferiority for the children from lack of confidence and questioning about their self-value [5].

\subsection{Inferiority with adolescents}

Most of the people had been somehow experienced inferiority on different level. This is extremely common towards humans; However, the characteristics of inferiority towards adolescents are more apparent [9]. Adolescents (age 15-17) are the age groups that enter puberty, which causes dramatic physical and mental changes [1]. Due to the unbalanced endocrine system and rapid physical changes of appearances, this distinct age group has constant fluctuating emotions and is usually more sensitive towards appearances, attraction towards the opposite sex, cognitive development towards society and environment, also other consequences due to puberty. Subsequently, adolescents are the essential group of people who either gets no effect from inferiority or gets seriously affected by inferiority feelings as time passes by [3]. It is more readily for adolescents than any other age stage to lead 
to an inferiority complex from inferiority feelings. This invisible grenade can trigger anxiety, depression, and other mental disorders, which diminishes one's quality of life severely [6].

\section{THE CAUSE OF ADOLESCENTS' INFERIORITY}

\subsection{Family factors}

\subsubsection{Family structure and parenting.}

The cross-sectional data collection used FIS, EPQ, and EMBU as the survey method tools. The experimental survey done by Wang et al. was towards 303 mid-school students (152 male and 151 female) from school at Jilin, China. They established 318 surveys in total, and the actual practical study was 303 . The experimental result data has the practicality rate of $96.86 \%$ from Wang et al. and acknowledged that few types of family structure were positive relative to the speed of emerging inferiority [12].

Since family and family relatives are the only small community that children can get in touch with, the cause of inferiority is often due to the original family. Family structures being the composition of family members. Three-generation families, where grandparents and the youngest generation live together, are prevalent in China.

Different types of family structures generate apparent differences in inferiority levels occurred with adolescents [12]. The effecting factors of varying family structures that causes inferiority to include: remarried family or family consist education background deficiency; remarried family due to exterior appearance; living in the combination of a family relative, friends or step-parents; three-generation (three-generation living together) and parents remarried families; parents with physical deficiency or caused divorced families; threegeneration, divorced families; sutteeism families. Above all the factors, the most problematic children compared with children from complete families are from the family of divorced and remarried family and family of 1 step-parents or living with family relatives [12].

\subsubsection{Parenting}

Parents and relatives are the exclusive groups of people adolescence in touch with; children are usually fully controlled by parents [12]. There are some observations of children's education, which American psychologists have separated two aspects of parenting, including innate and adaptation. The way of parenting can be split into four typical types; authoritative, autocratic, coddling, neglectful [12], and each class will cause distinct characteristics of the kids. Out of the four types, families that kept neglecting the children, presenting the lack amount of love, at the same time, did not demand their children for any aims. This type of parent often neglects all the needs of the children except the basic physiological needs.

Consequently, children who grew up with these kinds of parenting usually have difficulties adapting to the environment and lack self-discipline. In other words, the sort of parenting children have received can cultivate a harmful habit or characteristics that generate the burgeon of inferiority. From the experiment of Wang et al., the children from a family with a father are continuously rejective. Subsequently, adolescences with a higher chance of experiencing inferiority also relate to poor parenting [12]

\subsubsection{Economic background}

The community and the studying or living environment also produce inferiority mainly because of the people individuals stay in contact with. On the other hand, economic being the fundament of survival in modern society, the economic level of a family more or less affects the vague current hierarchy, which impacts the individual. In this case, adolescents in families with lower financial basics will automatically be the weaker group of society. The disadvantages caused by economic position are not a direct reason for inferiority. However, as individuals grow up from a less affluent family, this disenables the children to experience great things that their peers might have experienced; it also disables them to develop and maximize their potentials. Due to the limited horizon, this might cause adolescents (the age of identity cohesion vs role confusion) to have frustration for their economic position. By the collected data from using FIS to the mid-school children, it is indeed that individuals from the city have less chance of having inferiority than children from the suburb and rural areas. When adolescents grow up in poverty, then they would generate an insane desire for wealth. This extreme desire for wealth is a form of inferiority because wealth compensates for the poverty they experienced [13]

\subsection{Individual factors}

\subsubsection{Innate personality and characteristic}

The cause of inferiority usually relates to innate personality, which is also associated with family or relatives. At the same time, characteristics such as social ability, exterior appearance, physical strength, and learning ability. Three factors out of the big five personality traits, an extravert, neuroticism, and openness, are the most apparent factors related to inferiority. According to the experiment done by Wang et al., extravert and openness are positively relative with the cause of inferiority, and neuroticism is negatively 
relative. Subsequently, though neuroticism is related to inferiority, it is not the direct cause of inferiority [12].

\subsubsection{Gender differences}

Social media deliver myriad messages about body shape and facial appearances that impact females more than men on the first stage [16]. Adolescents, the group of people still discovering their position in their community, can be readily influenced by the media. As they enter puberty, their physical appearances and gender characteristics develop rapidly. Females being mentally matured than males; girls will feel uncomfortable and generate a sense of inferiority during puberty. Therefore, it adolescents females are easier to feel inferiority. At the same time, the cultural deficiency of the idea that men being superior to women generate inferiority [5].

\subsubsection{Socialization and self-controlment}

There are two main causes of impact of generating emotions including inferiority of adolescents: socialization and self-controlment. As the ages increase, people have to learn adaptation towards the society, the strategies for accommodating emotions of adolescents get fixed and adroit. Socialization being the crucial ability for people to develop, due to the Chinese cultural background, it is even more important for adolescents to learn controlling emotions in the right condition. Therefore, the accommodating ability is selected as society develops [1].

Besides socialization, adolescents' development towards suppressing emotions can be the cause of impact by unmoderated repression towards impulsive mentality [4]. According to the experiment done by Deng et al. adult have stronger ability to moderate different emotions. As ages increase, the stronger the ability gets. in this case, the reduction is only occurred due to the repulsion toward the natural emotion complexes. Simultaneously, evolution psychology indicates that stimuli of negative emotion complex is a stimulus which cause direct eschew [1]. Due to the Chinese cultural background, the issue which people restrain any types of natural emotions is more familiar than most of the other people from a different cultural background. On the contrary of the western culture, where as individuals are encouraged to reveal to inborn personalities, Chinese (eastern) cultures would think that calmness from restraining extreme emotions is a superb ability. Alternatively, emotion regulation requires individuals to response to the impulsion and control by experiencing biological and mental expression [1].

\section{THE SOLUTION OF ADOLESCENTS' INFERIORITY}

\subsection{Rational emotive therapy}

Rational emotive therapy (REBT) is a well-known therapy with applications in the treatment of mental health issues. The therapy employs a variety of techniques to encourage the use of cognitive mediational strategies to guide individuals' behaviours. The essence of the therapy is to address the underlying causes of emotional disturbances, rather than the events themselves [27]. Faulty perceptions lead to irrational thinking because they are antiempirical, illogical, and self-defeating, ultimately promoting emotional disturbance [27].

With a large number of results from Gonzalez et al. meta-analysis, the result represented a high relevance of the strength with influence of study characteristics on the treatment effectiveness of REBT for children and adolescents [27].

\subsection{Cognitive behaviour therapy}

Cognitive behavioural therapy (CBT), established by American psychologist being a widely implemented therapy to treat variety mental disorders. It has been a structural, short-term methods that solves the issues from changes with patients made to themselves, changes of perspectives [26]. The cognitive therapeutic techniques include self-monitoring of thoughts, feelings, and behaviour and cognitive restructuring [28]. More than sixty percent of children and adolescents treated with CBT no longer meet the Diagnostic and Statistical Manual of Mental Disorders (DSM) criteria for their primary disorder at post-treatment [29]. The therapy supports adolescents struggling with inferiority to conquer a negative mind pattern, low self-value, and elevate self-images [26].

\subsection{Group Counselling}

Counselling aims to create a benign relationship between the group members, and encourages the patient to discover their perspectives to appropriately view themselves and elevate the ability to make changes. The effectiveness of group counselling is dependent on the interaction between the counsellor and the group, and the counsellor's mode, concept, and effectiveness in leading the group are all closely related to the counsellor's personality and behavioural characteristics. As a qualified group counselling teacher, the following roles are required: initiator, motivator, moderator, observer, and commentator [31].

Group counselling facilitates the growth and development. At the same time, has a significant effect towards adolescents with development, and the long- 
term effects of self-confidence, shyness, social avoidance and distress [30].

\subsection{Adlerian Play Therapy}

Adlerian Play therapy (AdPT) as a therapeutic intervention of individual psychology for children treats inferiority on the essence. AdPT incorporates nondirective and directive play techniques to help children and adolescents to gain a deeper understanding of how they view themselves, others, and the world, and facilitates rehearsal of their changing perception [32]. The Adlerian practitioner stresses social interest through active friendship and genuine encounters between therapist and client [6]. The therapy would be the procedure for the therapists to encourage and foster the client to cultivate their connection towards cognitive changes and an awareness of their lifestyle [6]. The therapy contains four phases: establishing the relationship between patient and client; taking assessment; create insight; and develop a reorientation plan [6]. It emphasizes pragmatic approaches and solutions to psychological issues [7]. Therapists use Adlerian therapy to treat children at the same time change the behavior of parenting, prevent mental illness from poor parenting. Initial support for Ashby et al.'s contention AdPT can have a positive impact on adolescents came from parent and teacher accounts. Despite the fact that child self-report evaluations show no improvement in target behaviors as a result of AdPT, parent and teacher comments showed that practitioners should consider utilizing AdPT with children who have negative mental disorders that are similar to inferiority [32].

\section{CONCLUSION}

Inferiority is a type of negative emotion that could be the derivative of low self-esteem, inaccurate selfvalue, and other severe mental disorders. It is relatively more common to occur during the adolescence stage. The potential theoretical causes include ways of parenting, individual factors, and other factors patients had experienced. Nonetheless, psychological treatments including rational emotive therapy, cognitive behavioural therapy, and other inferiority related therapy are examined and used over the past years acquiring significant results. Overall, this review was provided by a myriad of authoritative researchers in the psychology field, which explain and resolve the inferiority problems towards adolescents.

\section{REFERENCES}

[1] Wu, J. (2015). Pursuing the meaning of life [D]. NanJing Normal university.

[2] MelanieJ, V, Fennell, Fennell \& X. Zhou. (2001). Overcoming low self-esteem. China Light Industry
Press.

Retrieved from:

https://xueshu.baidu.com/usercenter/paper/show?p aperid $=84 \mathrm{aa} 0477 \mathrm{adde} 30 \mathrm{c} 0 \mathrm{~b} 5 \mathrm{f} 9 \mathrm{e} 0 \mathrm{c} 697 \mathrm{ca} 3 \mathrm{fcd} \&$ site =xueshu_se

[3] Li, Y. \& Kongh, K. (2010). Review of domestic research on low self-esteem. Psychology research (06), 21-28.

[4] Tang, S. (2012). Review of domestic and international research on low self-esteem. Caizhi. (31), 191-192.

[5] Liang, J. (2010). Study of the relationship between automated thinking, low self-esteem, and coping styles among college students. (Doctoral dissertation, Hebei Normal University).

[6] Lin, J. (2000). The generation of low self-esteem in adolescence, harm and overcome. Journal of Minjiang College (5). 1-2.

[7] Sawyer, S.M., Azzopardi, P. S., Wickremarathne D, \& Patton, G, C. (2018) The age of adolescence. Lancet Child Adolesc Health. 2018 Mar;2(3):223228. doi: 10.1016/S2352-4642(18)30022-1.

[8] Lu, D. (2002). Common psychological disorders of adolescent students and their causes and countermeasures. Chinese Journal of Education (3), $55-57$.

[9] Knight Z. G. (2017). A proposed model of psychodynamic psychotherapy linked to Erik Erikson's eight stages of psychosocial development. Clinical psychology \& psychotherapy, 24(5), 1047-1058 https://doi.org/10.1002/cpp.2066

[10] Alfer,Adler \& Huang, G. (2011). Defeat selfcontempt. ISBN.

[11] Lu, Y. (2017). Review of domestic research exploring low self-esteem. Caizhi journal (19), 246-246.

[12] Sun, C \& Liu, M. (2017). Low self-esteem and adjustment in new adolescents. Xibupige, 39(006), 162-162.

[13] Yu, J. (2012). Inferiority complex formation factors from the family environment. Science Education Guide, 000(011), 230-231.

[15] Xie Z. (1994). Regarding men as superior to women: impacts of Confucianism on family norms in China. China population today, 11(6), 12-16.

[16] Brewis, A. A., \& Bruening, M. (2018). Weight Shame, Social Connection, and Depressive Symptoms in Late Adolescence. International journal of environmental research and public 
health,

$15(5)$

891.

https://doi.org/10.3390/ijerph15050891

[17] Shi, C. (2008). Exploring the basic characteristics of good parents from the psychological education of American parents. Rural . Agriculture. Farmers (Version A).

[18] Deng, X. (2014). Developmental and Neural Mechanism of emtion Up-and Down-Regulation in Adolescence [D]. East China Normal University.

[19] Butler, E. A., Lee, T. L., \& Gross, J. J. (2009). Does expressing your emotions raise or lower your blood pressure? the answer depends on cultural context. J Cross Cult Psychol, 40(3), 510-517. to Chinese cultural environment

[20] Oppenheim, D., Koren-Karie, N., \& SagiSchwartz, A. (2007). Emotion dialogues between mothers and children at 4.5 and 7.5 years: relations with children's attachment at 1 year. Child Development, 78(1), 38-52.

[21] Coffey, C. E., Cummings, J. L. , Duffy, J. D. , Fink, M. , Lauterbach, E. C. , \& Lovell, M. R. , et al. (1995). Assessment of treatment outcomes in neuropsychiatry: a report from the committee on research of the american neuropsychiatric association. J Neuropsychiatry Clin Neurosci, 7(3), 287-289.

[22] Powers, Robert, \& L. (2014). Annual conference of the north american society for adlerian psychology, victoria, british columbia, may 12 , 2011. Journal of Individual Psychology.

[23] Carlson, P. J. (2005). Adlerian Therapy.

[24] Rothbart, M. K., Derryberry, D., \& Posner, M. I. . (1994). A psychobiological approach to the development of temperament. Journal of the American Medical Association.

[25] Carlson, S. M., \& Wang, T. S. (2007). Inhibitory control and emotion regulation in preschool children. Cognitive Development, 22(4), 489-510.

[26] Zeng, Y. (2013). Inferiority complex and cognitivebehavioral therapy for higher education students. Youth and society, 000(014), 99. Retrieved from: https://d.wanfangdata.com.cn/periodical/qnyshh20 1314081

[27] Joyce, \& Marie, R. (2012) Rational-emotive therapy with children and adolescents: Wiley.

[28] Sauter, F. M., Heyne, D. , \& Westenberg, P. M. . (2009). Cognitive behavior therapy for anxious adolescents: developmental influences on treatment design and delivery. Clinical Child and Family Psychology Review, 12(4), 310-335.
[29] Alfano, C. A., Ginsburg, G. S., \& Kingery, J. N. (2007). Sleep-related problems among children and adolescents with anxiety disorders. Journal of the American Academy of Child \& Adolescent Psychiatry, 46(2), 224-232.

[30] Mu, Z. (2008). A study on group counseling and the correction of students' low self-esteem. Mental health education in primary and secondary schools, 000(014), 13-16. Retrieved from: www.cnki.com.cn/Article/CJFDTotalZXXK200814008.htm

[31] Xing, X, \& Wang, X. (2003). A study of the longterm effects of group counseling on the influence of interpersonal interactions among college students. Psychology Development and Education (02), 74-80. Retrieved from: www.cnki.com.cn/Article/CJFDTotalXLFZ200302013.htm

[32] Akay, S., \& Bratton, S. (2017). The effects of adlerian play therapy on maladaptive perfectionism and anxiety in children: a single case design. International Journal of Play Therapy, 26(2), 96110. 